This is the authors' accepted manuscript for the article: Agliardi, E., Pinar, M. and Stengos, T. (2015) An environmental degradation index based on stochastic dominance. Empirical Economics, 48 (1), pp. 439-459.

The final publication is available at Springer via http://dx.doi.org/10.1007/s00181-014-0853-3 


\section{An environmental degradation index based on stochastic dominance}

\author{
Elettra Agliardi \\ University of Bologna*
}

\author{
Mehmet Pinar \\ Edge Hill University ${ }^{\dagger}$
}

May 25, 2014

\author{
Thanasis Stengos \\ University of Guelph $\ddagger$
}




\section{Introduction}

Traditionally, wealth stock estimates have focused on produced capital, intangible capital (human capital, social capital), health and the quality of institutions. Recently, the concept of genuine saving has been introduced (Hamilton 1994; Hamilton and Clemens 1999; Arrow et al. 2003; Arrow et al. 2004; Agliardi 2011; Arrow et al. 2012), which provides a broader indicator of sustainability, by evaluating changes in natural resources and environmental quality, in addition to the traditional measure of changes in produced assets, included in net saving, and human capital. In a recent work the World Bank (2010) has updated their previous empirical analysis (World Bank 1997 and 2006) in per capita terms in 120 countries for the year up to 2005, building on Hamilton and Clemens (1999), to estimate comprehensive investment, adding to net national saving the net additions to fossil fuels and minerals, forest cover, carbon in the atmosphere and public expenditures in education. It has been argued that growth in some countries is not sustainable because of depletion in stocks of natural resources and deterioration in the quality of environmental services (e.g., Millennium Ecosystems Assessment 2005).

Our paper complements the literature on genuine saving, since we aim at constructing a comprehensive measure of the main sub-components of wealth, or well-being. Stiglitz et al. (2009) pointed out eight dimensions to go beyond GDP for multidimensional well-being, and the dimensions include standards of living, health, education, present and future environmental conditions, among other dimensions. In this paper, however, we focus on one sub-component only, that is, the relative environmental degradation of a country. In particular, the worst-case scenario weighting scheme is proposed to construct an environmental degradation index, using an approach that relies on consistent tests for stochastic dominance efficiency (SDE hereafter). ${ }^{1}$ Then, this index could be considered as a sub-index and added to other existing indices, for example, such as Human Development Index (HDI) and a natural resource index, to find, with the same methodology, the worst-case and the best-case scenario composite indices, representing the extreme ends for the wealth of a country. Our framework yields an empirically implementable measure that can be applied also to cross-country comparisons.

There are already several indicators and assessment methodologies for evaluating in practice the performance of industries, cities and countries, at global, national and regional level, related to economic and environmentally sustainability. The United Nations Commission on Sustainable Development (UNCSD) has derived a list of about fifty indicators, where some of them are based on monetary aggregation methods and others on physical quantities (UNCSD 2001). Singh et al. (2012) provides a recent overview of a great number of indicators that are already common practice for policy-making.

Some of them are elaborated from national accounts. The demand for "green" national accounts has recently arisen because of a growing recognition that the system of national accounts (SNA) must include the use of the natural environment. Among the macroeconomic indicators, the environmentally adjusted net domestic product (eaNDP) is obtained by combining the conventional NDP with monetary values of environmental degradation. Greened economy net domestic product (geNDP) estimates national income in a hypothetical future in which the economy must meet certain environmental standards and the impact is estimated by internalizing the costs of reducing environmental degradation. Sustainable national income (SNI) estimates the maximum level of national income that would be obtained if the economy met all environmental standards using the current technology. Additionally, from the system of environmental and economic accounts, single

${ }^{1}$ Throughout the paper the expression "stochastic dominance efficiency" refers to the data-driven statistical efficiency, rather than technical or environmental "efficiency", where the efficiency is measured as minimum feasible use of an environmentally detrimental input to produce a given output. 
indicators are obtained for different themes (e.g., acidification of the atmosphere, eutrophication of waters, and so on) by aggregating the emissions, using some common measurement unit and then comparing them with a national target level.

Finally, some composite indices have been obtained, by simple aggregation of the important issues. For example, the environmental sustainability index (ESI) is a measure of overall progress towards environmental sustainability (Esty et al. 2005), comprising a set of 21 sub-indicators, each of which combines two to six variables. The index of environmental friendliness (IEF) is based on aggregation of direct and indirect data related to global and local environmental problems, of greenhouse effect, acidification, eutrophication, biodiversity, and so on (see Puolamaa et al. 1996). Furthermore, the FEEM sustainability index (FEEM SI) aggregates 19 indicators that are allocated under three main pillars: environmental, social and economic to obtain relative and overall sustainability levels for countries and macro-regions (see Carraro et al. 2012; Pinar et al. 2014).

Although the above mentioned indicators and descriptive statistics have been provided in environmental accounts, there is no consensus over which indicators to use. Moreover, each indicator serves a somewhat different policy purpose. A further shortcoming is that the separate analysis of single indicators, or the composite measures listed above, ignore the dependence among the various components. Indeed, most indices are not able to take into account the interlinkages and dynamic interrelations of the various components. The majority of the indices used in the literature are either aggregated through equal weights assignments (e.g., ESI) or weights selected by experts (e.g., IEF and FEEM SI), or based on surveys of preferences of individuals, or from public opinion polls. Put in another way, they are often based on arbitrary weighting of the relevant variables.

If the indices are poorly constructed, or the weighting of the relevant variables is arbitrary, then the indices may potentially provide misleading results. Thus, evaluating the appropriate weighting and understanding the degradation of environmental indicators over time and the relative risk that these indicators point out, is increasingly recognized as urgent. In this paper, therefore, we analyze the progress of environmental indicators over 20 years and construct a relative worst-case environmental degradation index for different countries over the last two decades. We normalize the environmental indicators with the maximum level of environmental degradation level in each respective dimension, therefore the environmental risk in this paper measures the relative risk across countries. Such an index would be a useful tool for policy makers, allowing for a quick assessment of sustainability performance across different countries and at different times. It provides the worstcase scenario, where environmental degradation is at its maximum, and highlights directions for policy makers to evaluate future assessments.

Agliardi et al. (2014) analyze the evolution over time for all types of GHG emissions and water pollution, and their over-time findings are complemented by pair-wise industry comparisons to determine the major contributors to GHG emissions and water pollution from 1990 to 2005 . They find that $\mathrm{CO}_{2}$ emissions not only contributes the most to the GHG emissions over time, but also increased within 15 years in a first-order SD sense. On the other hand, water pollution increased in a second-order SD sense.

Here we construct an aggregate index for assessing the environmental degradation of a country based on SDE analysis. Constructing an index based on SD analysis has advantages since the index will be efficient, in that it results from the least variable combination of components that offers the maximum level of relative environmental risk over time for each country or group of countries. Relatively large data sets are available, so that the weighting scheme is data driven. Moreover, the main attractiveness of the SDE application is that it is nonparametric; therefore, we do not impose explicit specifications for the preferences of individuals or stakeholders towards environmental degradation and there are no restrictions on the functional forms of probability distributions. In an application to optimal portfolio construction in finance, Scaillet and Topaloglou (2010) use SDE 
tests to compare a given portfolio with an optimal diversified portfolio constructed from a set of assets. Pinar et al. (2013) use a similar approach to construct the best-case scenario of the HDI. Agliardi et al. (2012) use SDE analysis to construct an optimal country risk index with differential component weights for economic, political, and financial risk indices.

It is worth pointing out that the linear aggregation techniques presuppose some levels of interactions among indicators (see, e.g., Decancq and Lugo 2013). A further parameterization of the linear aggregation could allow for different levels of substitutability or complementarity among indicators (see, e.g., Alkire and Foster 2011). Clearly, it is natural to expect that some pairs of indicators are complements, and others substitutes with different strengths. However, in the empirical literature, there is no clear evidence about the level of substitutability and complementarity across well-being or ill-being indicators. This would require a separate research agenda to analyze the set of indicators to determine the level of substitutability and complementarity. This future analysis would guide practitioners to take into account these interactions across indicators while conducting multivariate SD comparisons (see, e.g., Muller and Trannoy 2011). Given there is no clear guidance on the interaction of indicators, we take a neutral attitude towards the aggregation issue and we question the use of an arbitrary weight allocation in linear aggregation as we consider all possible weighting schemes to derive the worst case scenario for environmental degradation.

We construct a relative worst-case environmental degradation index from greenhouse gas (GHG) emissions, water pollution and net forest depletion, by employing consistent SDE tests. This index offers the maximum level of environmental degradation in a country for a given probability level relative to the maximum attainable levels of each dimensions, being also the least volatile over time, among its set of competitors. In this index the environmental dimension that receives a higher weight suggests that for the majority of countries the degradation level that they reach is closer to the maximum attainable level in that dimension, when compared to the other dimensions, and, therefore, if one were to take a global action in any dimension, a priority should be given to the dimension whose weight is the highest.

Then, countries are ranked according to their environmental degradation index and a comparison with alternative rankings (e.g. the ranking of the Kyoto Protocol, Annex I or ESI rankings) can be performed. When GHG emissions, water pollution and net forest depletion are considered for the overall environmental degradation index, we find that GHG emissions contribute the most with a weight around $68 \%$, while the contributions of net forest depletion and water pollution are about $30 \%$ and $2 \%$, respectively. This finding suggests that there exist relatively more countries whose emissions are closer to the highest attainable GHG emissions dimension, when compared with other dimensions. Therefore, if one were to take a global action, more attention should be addressed to GHG emissions, as there are more countries contributing close to the highest attainable emission levels compared to the other dimensions. Furthermore, given the set of weights to each environmental degradation dimension, we find that the riskiest country in 2000 was the United States and in 2005 the riskiest country was China. Moreover, over time comparisons release information that there has been a deterioration in risk levels for 48 countries among 57 countries between 2000 and 2005 mainly due to major increases in the emissions and net forest depletion levels.

The plan of the paper is as follows. Section 2 presents the SDE methodology to construct the overall environmental index. Section 3 discusses the data and the empirical results and finally Section 4 concludes. In the Appendix we provide details about our data sources. 


\section{The SD Efficiency methodology}

In this section we present the test statistic for the SDE of the environmental degradation index constructed from GHG emissions, water pollution and net forest depletion. Let us consider a strictly stationary process $\left\{\boldsymbol{Y}_{t} ; t \in \mathbb{Z}\right\}$ with values in $\mathbb{R}^{n}$. The observations consist in a realization of $\left\{\boldsymbol{Y}_{t} ; t=1, \ldots, T\right\} . n$ represents the different constituent components, that is, total GHG emissions, water pollution and net forest depletion, where $T$ is the total number of observations consisting of panel data set of countries, sum of countries over a given period of time. We denote by $F(\boldsymbol{y})$, the continuous cdf of $\boldsymbol{Y}=\left(Y_{1}, \ldots, Y_{n}\right)^{\prime}$ at point $\boldsymbol{y}=\left(y_{1}, \ldots, y_{n}\right)^{\prime}$. A possible set of combinations of these components assigns them equal weights, as to represent equal importance of each of them (e.g. like in HDI or ESI). We take the equally-weighted index $(\tau)$ as a benchmark to test the argument whether the equally-weighted index is SD efficient, or a different set of weights would allocate relatively more risk. Let us consider an alternative environmental degradation index $\boldsymbol{\lambda} \in \mathbb{L}$, where $\mathbb{L}:=\left\{\boldsymbol{\lambda} \in \mathbb{R}_{+}^{n}: \boldsymbol{e}^{\prime} \boldsymbol{\lambda}=1\right\}$ with $\boldsymbol{e}$ for a vector made of ones. Let us denote by $G(z, \boldsymbol{\lambda} ; F)$ the cdf of the composite degradation index value $\boldsymbol{\lambda}^{\prime} \boldsymbol{Y}$ at point $z$ given by $G(z, \boldsymbol{\lambda} ; F):=\int_{\mathbb{R}^{n}} \mathbb{I}\left\{\boldsymbol{\lambda}^{\prime} \boldsymbol{u} \leq z\right\} d F(\boldsymbol{u})$ where $\mathbb{I}$ denotes the indicator function $\mathbb{I}\left(\boldsymbol{\lambda}^{\prime} \boldsymbol{u} \leq z\right.$ ) (Davidson and Duclos 2000). ${ }^{2}$

Define for $z \in \mathbb{R}$ :

$$
\begin{aligned}
& \mathcal{J}_{1}(z, \boldsymbol{\lambda} ; F):=G(z, \boldsymbol{\lambda} ; F), \\
& \mathcal{J}_{2}(z, \boldsymbol{\lambda} ; F):=\int_{-\infty}^{z} G(u, \boldsymbol{\lambda} ; F) d u=\int_{-\infty}^{z} \mathcal{J}_{1}(u, \boldsymbol{\lambda} ; F) d u,
\end{aligned}
$$

and so on.

Following Davidson and Duclos (2000) we obtain:

$$
\mathcal{J}_{j}(z, \boldsymbol{\lambda} ; F)=\int_{\mathbb{R}^{n}} \frac{1}{(j-1) !}\left(z-\boldsymbol{\lambda}^{\prime} \boldsymbol{u}\right)^{j-1} \mathbb{I}\left\{\boldsymbol{\lambda}^{\prime} \boldsymbol{u} \leq z\right\} d F(\boldsymbol{u}) .
$$

The empirical counterpart is simply obtained by integrating with respect to the empirical distribution $\hat{F}$ of $F$, which yields:

$$
\mathcal{J}_{j}(z, \boldsymbol{\lambda} ; \hat{F})=\frac{1}{T} \sum_{t=1}^{T} \frac{1}{(j-1) !}\left(z-\boldsymbol{\lambda}^{\prime} \boldsymbol{Y}_{t}\right)^{j-1} \mathbb{I}\left\{\boldsymbol{\lambda}^{\prime} \boldsymbol{Y}_{t} \leq z\right\}
$$

where $\mathbb{I}$ denotes the indicator function $\mathbb{I}\left(\boldsymbol{\lambda}^{\prime} \boldsymbol{Y}_{t} \leq z\right)$ and $\widehat{F}(z)=\frac{1}{T} \sum_{i=1}^{N} \mathbb{I}\left(X_{i} \leq z\right)$ is the empirical distribution of $F$ (Davidson and Duclos 2000) and can be rewritten more compactly for $j \geq 2$ as:

$$
\mathcal{J}_{j}(z, \boldsymbol{\lambda} ; \hat{F})=\frac{1}{T} \sum_{t=1}^{T} \frac{1}{(j-1) !}\left(z-\boldsymbol{\lambda}^{\prime} \boldsymbol{Y}_{t}\right)_{+}^{j-1} .
$$

The test statistics and the asymptotic distribution of $\hat{F}$ are discussed in Scaillet and Topaloglou (2010). In particular, we follow Scaillet and Topaloglou (2010) and consider the weighted KolmogorovSmirnov type test statistic

$$
\hat{S}_{j}:=\sqrt{T} \frac{1}{T} \sup _{z, \boldsymbol{\lambda}}\left[\mathcal{J}_{j}(z, \boldsymbol{\tau} ; \hat{F})-\mathcal{J}_{j}(z, \boldsymbol{\lambda} ; \hat{F})\right],
$$

\footnotetext{
${ }^{2} \tau$ and $\lambda$ represent weighting vectors. However, throughout the paper, for simplicity, we use $\tau$ and $\lambda$ for the index that they represent.
} 
and a test based on the decision rule:

$$
\text { " reject } H_{0}^{j} \text { if } \hat{S}_{j}>c_{j} "
$$

where $c_{j}$ is some (appropriate) critical value. In order to make the result operational, we need to find an appropriate critical value $c_{j}$. Since the distribution of the test statistic depends on the underlying distribution, we rely on a block bootstrap method to simulate p-values (see Sect. 3 of Scaillet and Topaloglou 2010 for block bootstrap methods). Since the test statistics for first- and second-order SDE rely on all possible weighting schemes for all possible degradation levels, test statistics for each case are obtained through a maximization problem implemented by mixed integer and linear programming respectively (see Sect. 4 of Scaillet and Topaloglou 2010 for the details of the derivation of the mathematical formulations of the first- and second-order of SDE).

The hypotheses for testing whether the equally-weighted environmental degradation index, $\boldsymbol{\tau}$, is relatively the worst-case scenario is as follows:

$$
\begin{gathered}
H_{0}^{j}: \mathcal{J}_{j}(z, \boldsymbol{\tau} ; \hat{F}) \leq \mathcal{J}_{j}(z, \boldsymbol{\lambda} ; \hat{F}) \text { for all } z \in \mathbb{R} \text { and for all } \boldsymbol{\lambda} \in \mathbb{L} \\
H_{1}^{j}: \mathcal{J}_{j}(z, \boldsymbol{\tau} ; \hat{F})>\mathcal{J}_{j}(z, \boldsymbol{\lambda} ; \hat{F}) \text { for some } z \in \mathbb{R} \text { or for some } \boldsymbol{\lambda} \in \mathbb{L} .
\end{gathered}
$$

Under the null Hypothesis $H_{0}^{j}$ there is no composite degradation index $\boldsymbol{\lambda}$ constructed from the set of components, or environmental degradation (risk) factors, that dominates the index $\boldsymbol{\tau}$ at order $j$. In this case, $\mathcal{J}_{j}(z, \boldsymbol{\tau} ; F)$ is always lower than $\mathcal{J}_{j}(z, \boldsymbol{\lambda} ; F)$ for all possible indices $\boldsymbol{\lambda}$ for any $z$. Under the alternative hypothesis $H_{1}^{j}$, a composite degradation index $\boldsymbol{\lambda}$ exists, such that for some $z$, $\mathcal{J}_{j}(z, \boldsymbol{\tau} ; F)$ is larger than $\mathcal{J}_{j}(z, \boldsymbol{\lambda} ; F)$. Thus, when $j=1$, the index $\boldsymbol{\tau}$ is stochastically inefficient at first-order if and only if some other index $\lambda$ dominates it at some $z$. Put in another way, the index $\boldsymbol{\tau}$ is stochastically efficient at first order if and only if there is no index $\boldsymbol{\lambda}$ that dominates it at all levels of environmental degradation (risk) levels. SD efficiency tests can be specified at first- and second-order when $j=1$ and $j=2$, respectively.

\section{Empirical Analysis}

\subsection{Data and Descriptive Statistics}

The data set used in this paper consists of total GHG emissions, water pollution and net forest depletion for several countries in various years, between 1990 and $2010 .{ }^{3}$ The main source for our data is The World Bank, Policy and Economics Environment Department. ${ }^{4}$ All data are categorized in and obtained from World Development Indicators. GHG emissions consist of $\mathrm{CO}_{2}$, methane, nitrous oxide and other GHG emissions. For the overall environmental degradation index, emission types are summed as all of them are measured in $\mathrm{CO}_{2}$ equivalent levels. Water pollution consists of yearly emissions of organic water pollutants and is measured by biochemical oxygen demand, which is the amount of oxygen that bacteria in water will consume in breaking down waste. Finally, net forest depletion comes from genuine saving data set of the World Bank and is measured by the product of unit resource rents and the excess of roundwood harvest over natural growth in current US\$ (see Kunte et al. 1998 for the calculation of net forest depletion). Notice that not all countries have

\footnotetext{
${ }^{3} \mathrm{CO}_{2}$ emissions consist of annual data from 1960 to 2009, whereas methane, nitrous and other GHG emissions consist of data in 1990, 1995, 2000 and 2005. We have annual data for water pollution from 1986 to 2007. Finally, net forest depletion data are available annually from 1970 to 2010 .

${ }^{4}$ The authors are indebted to Glenn-Marie Lange and her staff members at The World Bank for their help in providing most data.
} 
available data for all variables (e.g., China, one of the main contributor to GHG emissions, has not released data for water pollution in 2000, whereas India, the main contributor to net forest depletion, has not released data for water pollution over the whole period), which implies that only countries whose data are available for all variables will be ranked in the overall environmental degradation index. A detailed availability of all the variables used and the normalization procedure for the environmental degradation variables are presented in Tables A1 and A2 (Appendix A), respectively.

\subsection{Stationarity of the environmental degradation indices}

After converting each environmental degradation variable into an index, prior to the SD efficiency analysis, we test for the stationarity of the index series. In the current application, we employ the environmental degradation indicators (i.e., total GHG emissions, water pollution and net forest depletion) to analyze the overall risk for all countries rather than analyzing individual variables for given countries alone. Therefore, for the purpose of the current application, we test for stationarity of the environmental degradation indicators when all countries are considered together. We should note that even though some variables for some countries may be non-stationary, when these variables are put together at an aggregate (cointegrated) level, then the linear combination of these variables is stationary.

We proceed to examine whether the degradation risk variables follow a stationarity process by using standard Augmented Dickey-Fuller (ADF) unit root tests. To do so, we employ three different ADF lag length selection criteria, the Schwartz information criterion (SBIC), the Akaike's information criterion (AIC), and the Hannan and Quinn information criterion (HQIC). The test statistics for each test for each variable are reported in Table 1. Overall, we find that all environmental degradation variables follow a stationary process and therefore we can proceed to apply the Scaillet and Topaloglou (2010) methodology to test for SDE of the equally-weighted environmental degradation risk index.

We should note that when all countries are put together to construct an environmental degradation index, the data follow a stationary process. However, if one were to analyze environmental degradation for a given country, a different SD methodology could be employed if the variables for that country were to follow a unit root process. In other words, if one were to analyze country specific environmental degradation, rather than using the SDE approach, one could instead employ the Linton et al. (2005) consistent SD testing approach, which allows for dependence over time. However, in the present study we examine the overall environmental degradation risk for all countries under consideration rather than conducting an individual country analysis. Since the environmental degradation variables follow a stationary process when all countries are taken together, we employ the SDE methodology to test whether the use of the equally-weighted environmental degradation index constitutes the worst case scenario or we can alternatively derive another weighting scheme which will provide the worst case scenario for the group of countries under consideration. Below, we present the worst-case composite index for environmental degradation and the country rankings based on of that index.

\subsection{SD efficient environmental degradation index}

In a recent paper, Agliardi et al. (2014) examined the evolution over time of GHG emissions and water pollution. It is found that there was a general deterioration in $\mathrm{CO}_{2}$ emissions in the last 15 years and, at the same time, water pollution increased in this period for some but not for all countries. Given the over-time deterioration in these dimensions, we conduct SDE analysis to create an overall index of environmental degradation. 
The variables used for overall degradation index are the total GHG emissions (i.e. sum of $\mathrm{CO}_{2}$, methane, nitrous oxide, other GHG emissions), total water pollution (i.e. total emissions of organic water pollutants), total net forest depletion values. We consider net forest depletion as to account for the depravation activity, water filtration, erosion control etc. that forests provide. According to the World Bank definition, greenhouse $\left(\mathrm{CO}_{2}\right)$ emissions measured in kilotons (kt) are stemming from the burning of fossil fuels and the manufacture of cement. They include contributions to the carbon dioxide produced during consumption of solid, liquid, and gas fuels and gas flaring. $\mathrm{CO}_{2}$ is a stable gas which is not transformed chemically in the atmosphere. However, some $\mathrm{CO}_{2}$ is removed from the atmosphere by a natural process that includes the effect of vegetation, soils and oceans. Moreover, human activities such as reforestation, deforestation or land management may increase or decrease the amount of $\mathrm{CO}_{2}$ removed from the atmosphere. ${ }^{5}$ Therefore, the higher the values for each component (i.e. GHG emissions, water pollution, and net forest depletion), the higher is the environmental degradation. Since each indicator is measured in different units, prior to the SDE tests, we normalize each indicator by dividing each country's value in each index by the highest total value in that index.

We conduct the test for the first-order SDE of overall environmental degradation index. ${ }^{6}$ Table 2 is obtained combining the three sub-indices to find a weighting scheme for each sub-index which will offer the maximum level of environmental degradation (risk) over time for each country or group of countries, when compared with all other possible weighting schemes of each index. Table 3 provides the rankings of the various countries in terms of the worst-case environmental degradation index for years 2000 and $2005 .{ }^{7}$ Our findings suggest that the GHG emissions contribute the most with $67.5 \%$, whereas net forest depletion contributes with $30.3 \%$, and water pollution contributes with $2.2 \%$ to the worst-case environmental degradation index. We can observe that the ranking remains more or less stable over the years.

As the components are normalized with the maximum level of environmental degradation level in each respective dimension, the environmental risk in this paper measures the relative risk across countries. Therefore, the environmental dimension that receives a higher weight suggests that for the majority of countries the degradation level that they reach is closer to the maximum attainable level in that dimension, when compared to the other dimensions. In our application, GHG emissions are the riskiest, when compared to the other dimensions. Thus, almost all countries have been releasing GHG emissions that are relatively closer to the maximum attainable level in the GHG emissions dimension. The water pollution component has a relatively small weight in the overall index because, in comparative terms, it is a slower-moving variable when all countries are considered altogether over the whole period. Actually, it has been shown that during a similar period while $\mathrm{CO}_{2}$ emissions increased in a first-order SD sense, water pollution increased only in a second-order SD sense (Agliardi et al. 2014). It implies that for some countries water pollution improved over time and deteriorated for others (even though it increased globally). When we consider an overall degradation index, big improvements/deteriorations in individual countries smooth down and water pollution becomes a relatively stable variable over time (i.e., a slow-moving variable). Further

\footnotetext{
${ }^{5}$ For example, the global natural $\mathrm{CO}_{2}$ removal rate for the set of countries that we examine has been estimated to be around 60 percent for the period 1990 to 2000, see IPCC, 2000. See http://unfccc.int/ghg_emissions_data/predifined_qeuries/items/3814.php

${ }^{6}$ We first test for stochastic dominance efficiency at the first-order: if there is dominance at first-order, then there will be dominance at any other greater order. If not, then we continue for stochastic dominance efficiency for higher orders.

${ }^{7}$ We have overlapping data for 1990, 1995, 2000 and 2005 for all environmental quality indicators. We only reported 2000 and 2005 rankings for two reasons. We have only 8 overlapping countries in 1990, therefore we have not reported the ranking in that year. On the other hand, even though 1995 consists of 41 overlapping countries, we do not have data for water pollution data for major countries, United States, Russian Federation and China.
} 
analysis shows that nowadays, for any water pollution level, food industry pollutes water more than chemical, textile and other industries (such as clay and glass, metal, paper, and wood industries), which were heavy pollutants, traditionally. "Free riding" or other externalities in water pollution may be the cause of such changes over time, but also environmental regulations and new abatement technologies have become more effective to combat water pollution in some countries. ${ }^{8}$

On average, the countries with higher values in the worst-case environmental degradation index are China, the United States, Ethiopia, South Africa, Russian Federation and Japan, but also other countries, such as Thailand, Germany, Vietnam, United Kingdom, Canada and France, are ranked as worst offenders, or polluters. Furthermore, we observe that among the 57 countries for which we have full information for 2000 and 2005, we had 48 countries for which environmental quality deteriorated, while it improved for the remaining 9 countries. Therefore, there was an overall deterioration in the environmental quality. Table 4 summarizes the changes between 2000 and 2005 for the countries for which we have full information. For some countries we only have partial information and hence they are not used in this comparison. For example, China (i.e., main contributor to emissions) is missing in the ranking in 2000. Countries which experienced a major deterioration between 2000 and 2005 are South Africa, Ethiopia, Sweden, Poland, Slovak Republic, Malaysia, Indonesia, Russian Federation and Iran, where all of them experienced increases in their GHG emissions. However, most deterioration for South Africa, Ethiopia, Sweden, Poland, Slovak Republic and Malaysia is due mainly to increases in their net forest depletion levels. ${ }^{9}$ On the other hand, Vietnam and Estonia improved their position, due to improvement in net forest depletion as net forest depletion of Vietnam and Estonia decreased from 220 and 55 million US\$ to 112 and 2 million US\$ respectively from 2000 and 2005.

Furthermore, observe that our ranking differs from that of the commitments of countries in the Kyoto Protocol. It is well known that the Kyoto Protocol establishes assigned amounts of emissions for various countries (see Annex I and Annex $\mathrm{B}^{10}$ ), with the intention of reducing their average emissions during 2008-2012 to about 5 percent below 1990 levels. Under the Kyoto Protocol, only the Annex I countries have committed themselves to national or joint reduction targets that range from a joint reduction of $8 \%$ for the European Union (originally only the 15 states that were EU members in 1997, when the Kyoto Protocol was adopted), of $7 \%$ for the United States, $6 \%$ for Japan, Canada, Hungary and Poland, $5 \%$ for Croatia, and $0 \%$ for New Zealand, Russia and Ukraine; moreover, a $+1 \%$ was allowed to Norway, $+8 \%$ for Australia and $+10 \%$ for Iceland. The rankings we obtain in Table 3 remained substantially stable over the two periods. Notice that the following countries have the highest values of the overall worst-case environmental quality: China, the United States, Ethiopia, South Africa, Russian Federation, the United States, and Japan. This list does not overlap with the groups of countries adopted by the Kyoto Protocol - in particular, China, Ethiopia, South Africa, and Russian Federation are the main polluters in our rankings.

We also conducted ranking comparisons of our worst-case environmental degradation index with the ESI rankings (see Esty et al. 2005) in 2005. ESI integrates 76 data sets by tracking natural resource endowments, past and present pollution levels, environmental management efforts, and the capacity of a society to improve its environmental performance into 21 indicators of environmental sustainability index combining them with equal weights for 146 countries. ESI gives scores between 0 and 100 and a higher index value represents a better environmental condition for a country. Since our index represents the riskiest environmental quality (i.e., worst-case environmental degradation),

\footnotetext{
${ }^{8}$ Sigman (2002) finds that there is less free riding in water quality within European Union, suggesting that international institutions might work as mitigating factors.

${ }^{9}$ Net forest depletion for South Africa, Ethiopia, Sweden, Poland, Slovak Republic and Malaysia increased from around $35,713,0,0,100$, and 80 million US\$ to $65,886,155,120,213$, and 162 million US\$ respectively.

${ }^{10}$ See http://unfccc.int/kyoto_protocol/items/2830.php
} 
we converted the ESI measure by subtracting its score from 100 to represent ESI ranking from the riskiest to the least risky country to compare the two rankings. Table 5 presents the rankings of the overlapping 61 countries in both rankings. The rankings differ significantly, especially when it comes to the environmentally riskiest countries (i.e., countries that pollute the environment the most). Even though ESI covers 21 indicators, yet they do not capture total contributions to the environmental degradation but are normalized with per capita or percentage values. Moreover, ESI does not cover net forest depletion and water pollution values. Table 6 presents Spearman correlations between ESI rankings and our overall worst-case environmental degradation index and its sub-indices. We find that only the GHG emissions is weakly correlated with the ESI rankings as the correlation between ESI and GHG emission rankings is positive and significant at the $10 \%$ significance level. However, there has been no significant correlation between total water pollution and the ESI rankings, and net forest depletion and ESI rankings. As there is no significant correlation between our overall environmental degradation index and ESI rankings, there exist some major relative rank reversals. The riskiest five countries in our worst-case environmental degradation index (i.e., worst offenders) are China, the United States, Ethiopia, South Africa, and Russian Federation, whereas ESI ranked these countries as 4th, 37th, 2nd, 17th, and 44th, respectively. Even though China and Ethiopia ranked in high positions in both rankings, the remaining countries experienced a lower ranking in ESI.

\section{Conclusions}

Our main result in this paper is the derivation of a worst case scenario environmental degradation index based on SD analysis with differential component weights that will offer the maximum level of environmental degradation (risk) for a country. When GHG emissions, water pollution and forest cover are considered for the overall environmental degradation index, total GHG emissions contribute the most with a weight of $68 \%$ and the contribution of net forest depletion and water pollution are $30 \%$ and $2 \%$, respectively. The relative worst-case scenario obtained in this paper can provide an important benchmark to assess the progress (or lack of it) that countries make in reducing their environmental risk, by trying to implement policies that improve on the dimensions that are mostly responsible for environmental degradation.

Cross-country differences in the worst-case environmental performance, as described by the rankings of our index, can be used to study the relations between environmental performance and (i) the standard of living (e.g., measured by GDP, HDI); (ii) economic development stages (from an environmental Kuznets curve standpoint), (iii) regulatory regimes (e.g., the presence of standards, implementation and enforcement mechanisms and associated institutions); (iv) legal context (e.g., protection of property rights, the extent of the rule of law, institutional quality). We can test whether alleviating poverty, introducing environmental regulations and strengthening countries' governance structures could constitute effective policy measures from the perspective of environmental progress.

Furthermore, our index could be employed as a covariate in regression analysis. This would be another added advantage for using the proposed index in empirical work as opposed to other possible indices based on arbitrary weights, since our SD based index will attain lower variability and, as such, will be less prone to measurement errors, something that may plague other indices. Below we provide a list of areas for the potential use of our index as a covariate (or as dependent variable) in empirical analysis.

Firstly, our index can be employed as a covariate to study the connection between environmental performance and living standards, through its impact on a country's capacity to sustain economic growth. There are two conflicting hypothesis. On the one hand, countries with high economic 
growth would be better able to combat environmental degradation because they have more financial resources. On the other hand, these countries have higher levels of consumption, leading to increasing environmental pollution. Even if both trends occur, it is possible to identify which one is dominating. The ability to grow requires resources and puts strains on the environment, driving up costs. At the same time, as some literature suggests (e.g., Esty and Porter 2005), economic competitiveness and environmental performance may be compatible, if not mutually reinforcing. Thus, policies that stimulate improvements in the environmental quality may actually foster competitiveness, leading to an increased standard of living in the long run. Secondly, our index could be used as a proxy for the worst-case environmental progress, and we could also test a weak version of the "Porter hypothesis" (Porter 1991; Porter and van der Linde 1995) - which argues that environmental progress can be achieved without sacrificing competitiveness - or a strong version of it - which argues that countries that achieved environmental progress will enhance their competitiveness. Thirdly, our index can be used in future work to test the hypothesis whether or not political factors affect different environmental performance and its change over time. Different policy regimes (i.e., social democratic government power, green parties, new politics mobilization) could have a significant impact for a successful environmental performance (see, e.g., Esping-Andersen 1990; Jahn 1998).

Finally, other than regression analysis, a possible future implication of our analysis is to monitor the evolution of the weights of our index which may be informative for policy purposes. This is a further by-product of our approach. Of course, more detailed environmental datasets (often not currently available) would be required at the global, national and local level if a more systematic approach to environmental improvement is to be implemented.

For possible future work one could also apply this methodology to obtain the worst-case (bestcase) composite index representing the most pessimistic (optimistic) measure of wealth for a country, or group of countries, representing the extreme ends for the wealth of a country. One could find the weighting scheme of each sub-index (i.e., of environmental quality, of natural resources, and HDI) which corresponds to the overall worst-case (best-case) for all countries. As Hamilton and Clemens (1999) state, "thinking about sustainable development and its measurement leads naturally to a conception of the process of development as one of portfolio management". This implies that one has to consider not only assets and liabilities in the national balance sheet (i.e., natural resources, produced assets, human capital and pollution stocks) but also their appropriate weights. Our approach provides this portfolio analysis and the weighting scheme consistent with the worst/best (pessimistic/optimistic) scenarios.

Finally, we should note that it is natural to expect that some factors of well-being (or ill-being) will be complements and others substitutes of each other. In order to take into account these interrelationships, future research would be required to identify the interactions between different sets of well-being (ill-being) indicators, either by adding extra set of variables into the linear aggregation procedure, or by applying non-additive aggregation techniques. For example, in the multivariate SD comparisons, these interrelationships could be taken into account by allowing second partial cross-derivatives to be positive (negative) when there is a complementarity (substitutability) across indicators.

\section{$5 \quad$ References}

Agliardi E (2011) Sustainability in uncertain economies. Environ Resour Econ 48:71-82

Agliardi E, Agliardi R, Pinar M, Stengos T, Topaloglou N (2012) A new country risk index for emerging markets: a stochastic dominance approach. J Emp Financ 19:741-761

Agliardi E, Pinar M, Stengos T (2014) Assessing temporal trends and industry contributions to 
air and water pollution using stochastic dominance. Environ Ecol Stat. Forthcoming

Alkire S, Foster J (2011) Counting and multidimensional poverty measurement. J Public Econ 95:476-487

Arrow KJ, Dasgupta PS, Mäler K-G (2003) Evaluating projects and assessing sustainable development in imperfect economies. Environ Resour Econ 26:647-685

Arrow KJ, Dasgupta PS, Goulder LH, Daily G, Ehrlich PR, Heal GM, Levin S, Mäler K-G, Schneider S, Starett DA, Walker B (2004) Are we consuming too much? J Econ Perspect 18:147-172

Arrow KJ, Dasgupta PS, Goulder LH, Mumford KJ, Oleson K (2012) Sustainability and the measurement of wealth. Environ Dev Econ 17:317-353

Barrett GF, Donald SG (2003) Consistent tests for stochastic dominance. Econometrica 71:71-104

Carraro C, Capagnolo L, Eboli F, Lanzi E, Parrado R, Portale E (2012) Quantifying sustainability: a new approach and world ranking. FEEM Working Paper No. 2012.94

Dasgupta PS (2001) Human well-being and the natural environment. Oxford University Press, Oxford

Davidson R, Duclos J-Y (2000) Statistical inference for stochastic dominance and for the measurement of poverty and inequality. Econometrica 68:1435-1464

Decancq K, Lugo MA (2013) Weights in multidimensional indices of well-being: An overview. Economet Rev 32:7-34

Esping-Andersen G (1990) The three worlds of welfare capitalism. Polity Press, Cambridge

Esty DC, Levy M, Srebotnjak T, de Sherbinin A (2005) 2005 Environmental sustainability index: benchmarking national environmental stewardship. Yale Center for Environmental Law \& Policy, New Haven

Esty DC, Porter ME (2005) National environmental performance: an empirical analysis of policy results and determinants. Environ Dev Econ 10:391-434

Hamilton K (1994) Green adjustments to GDP. Resour Policy 20:155-168

Hamilton K, Clemens M (1999) Genuine saving rates in developing countries. World Bank Econ Rev 13:333-356

Jahn D (1998) Environmental performance and policy regimes: Explaining variations in 18 OECD-countries. Policy Sci 31:107-131

Kunte A, Hamilton K, Dixon J, Clemens M (1998) Estimating national wealth: methodology and results. Environment Department Working Papers No. 57. Environmental Economics Series. World Bank, Washington

Linton O, Maasoumi E, Whang Y-J (2005) Consistent testing for stochastic dominance under general sampling schemes. Rev Econ Stud 72:735-765

MacKinnon J (1991) Critical values for cointegration tests. In: Engle R, Granger C (eds) Longrun economic relationships: readings in cointegration, Oxford University Press, Oxford, pp 267-276

Millennium Ecosystem Assessment (2005) Ecosystems and human well-being: synthesis. World Resources Institute, Washington

Muller C, Trannoy A (2011) A dominance approach to the appraisal of the distribution of wellbeing across countries. J Public Econ 95:239-246

Pinar M, Cruciani C, Giove S, Sostero M (2014) Constructing the FEEM sustainability index: A Choquet integral application. Ecol Indic 39:189-202

Pinar M, Stengos T, Topaloglou N (2013) Measuring human development: a stochastic dominance approach. J Econ Growth 18:69-108

Porter ME (1991) America's green strategy. Sci Am 264:168

Porter ME, van der Linde C (1995) Toward a new conception of the environment-competitiveness relationship. J Econ Perspect 9:97-118 
Puolamaa M, Kaplas M, Reinikainen T (1996) Index of environmental friendliness: A Methodological study. Eurostat

Scaillet O, Topaloglou N (2010) Testing for stochastic dominance efficiency. J Bus Econ Stat 28:169-180

Sigman H (2002) International spillovers and water quality in rivers: do countries free ride? Am Econ Rev 92:1152-1159

Singh RK, Murty HR, Gupta SK, Dikshit AK (2012) An overview of sustainability assessment methodologies. Ecol Indic 15:281-299

Stiglitz JE, Sen A, Fitoussi J-P (2009) Report by the commission on the measurement of economic performance and social progress

UNCSD (2001) Indicators of Sustainable Development: Guidelines and Methodologies. Commission on Sustainable Development, New York. http://www.un.org/esa/sustdev/natlinfo/indicators/indisd/indisdmg2001.pdf.

World Bank (1997) Expanding the measure of wealth: indicators of environmentally sustainable development. World Bank, Washington

World Bank (2006) Where is the wealth of nations? World Bank, Washington

World Bank (2010) The changing wealth of nations: measuring sustainable development in the new millennium. World Bank, Washington 


\begin{tabular}{|c|c|c|c|}
\hline & Index levels (SBIC) & Index levels (AIC) & Index levels (HQIC) \\
\hline Total GHG emissions & $-12.966^{*}$ & $-12.966^{*}$ & $-12.966^{*}$ \\
\hline Water pollution & $-12.973 *$ & $-12.973 *$ & $-12.973 *$ \\
\hline Net forest depletion & $-13.847 *$ & $-13.847 *$ & $-13.847 *$ \\
\hline \multicolumn{4}{|c|}{$\begin{array}{l}\text { Notes: Critical values of ADF are } 1 \%(-3.44) \text { and } 5 \%(-2.86) \text {, respectively, taken from MacKinnon } \\
\text { (1991). ADF lag length decision based on Schwartz information criterion (SBIC), Akaike's } \\
\text { information criterion (AIC), and the Hannan and Quinn information criterion (HQIC) (minimum lag } \\
=0 \text { and maximum lag }=4) . *, * * \text {, and } * * * \text { indicates significance at the } 1 \%, 5 \% \text { and } 10 \% \text { level of } \\
\text { rejecting the unit root process. The null hypothesis is that the variable suggests a unit root process } \\
\text { and the alternative is that the variable is generated by a stationary process. }\end{array}$} \\
\hline
\end{tabular}

\begin{tabular}{|c|c|c|c|c|}
\hline \multicolumn{2}{|c|}{ Table 2 Stochastic efficient weighting of sub-indices } \\
\hline $\begin{array}{c}\text { Number of } \\
\text { observations }\end{array}$ & $\begin{array}{c}\text { Number of } \\
\text { dominating } \\
\text { weighting } \\
\text { schemes }\end{array}$ & $\begin{array}{c}\text { Greenhouse } \\
\text { emissions }\end{array}$ & Water pollution & $\begin{array}{c}\text { Net forest } \\
\text { depletion }\end{array}$ \\
\hline $\mathrm{N}$ & $\mathrm{n}$ & Average of dominating weighting schemes \\
\hline 178 & 169 & 0.675 & 0.022 & 0.303 \\
\hline
\end{tabular}




\begin{tabular}{|c|c|c|c|c|}
\hline Country & $\begin{array}{c}\text { Environmental } \\
\text { degradation index } \\
\text { outcome in } 2000\end{array}$ & $\mathbf{N}$ & Country & $\begin{array}{c}\text { Environmental } \\
\text { degradation index } \\
\text { outcome in } 2005\end{array}$ \\
\hline United States & 0.5806 & 1 & China & 0.6970 \\
\hline Ethiopia & 0.2509 & 2 & United States & 0.5899 \\
\hline Russian Federation & 0.1940 & 3 & Ethiopia & 0.3108 \\
\hline South Africa & 0.1610 & 4 & South Africa & 0.2662 \\
\hline Japan & 0.1206 & 5 & Russian Federation & 0.2058 \\
\hline Thailand & 0.1129 & 6 & Japan & 0.1221 \\
\hline Germany & 0.0894 & 7 & Germany & 0.0868 \\
\hline Vietnam & 0.0885 & 8 & Poland & 0.0775 \\
\hline United Kingdom & 0.0603 & 9 & Malaysia & 0.0774 \\
\hline Canada & 0.0601 & 10 & Slovak Rep. & 0.0771 \\
\hline France & 0.0514 & 11 & Philippines & 0.0687 \\
\hline Indonesia & 0.0479 & 12 & Indonesia & 0.0605 \\
\hline Italy & 0.0478 & 13 & Sweden & 0.0594 \\
\hline Malaysia & 0.0437 & 14 & United Kingdom & 0.0581 \\
\hline Korea, Rep. & 0.0437 & 15 & Vietnam & 0.0579 \\
\hline Iran, Islamic Rep. & 0.0424 & 16 & Iran, Islamic Rep. & 0.0530 \\
\hline Ukraine & 0.0390 & 17 & Italy & 0.0497 \\
\hline Slovak Rep. & 0.0385 & 18 & France & 0.0481 \\
\hline Latvia & 0.0364 & 19 & Korea, Rep. & 0.0461 \\
\hline Poland & 0.0360 & 20 & Ukraine & 0.0395 \\
\hline Spain & 0.0326 & 21 & Latvia & 0.0390 \\
\hline Turkey & 0.0274 & 22 & Spain & 0.0381 \\
\hline Argentina & 0.0252 & 23 & Saudi Arabia & 0.0371 \\
\hline Croatia & 0.0212 & 24 & Croatia & 0.0311 \\
\hline Estonia & 0.0203 & 25 & Turkey & 0.0305 \\
\hline Netherlands & 0.0188 & 26 & Kazakhstan & 0.0214 \\
\hline Belgium & 0.0175 & 27 & Belgium & 0.0208 \\
\hline Kazakhstan & 0.0158 & 28 & Slovenia & 0.0199 \\
\hline Slovenia & 0.0135 & 29 & Czech Rep. & 0.0197 \\
\hline Czech Rep. & 0.0132 & 30 & Netherlands & 0.0188 \\
\hline Denmark & 0.0127 & 31 & Lithuania & 0.0174 \\
\hline Colombia & 0.0120 & 32 & Colombia & 0.0123 \\
\hline Romania & 0.0115 & 33 & Romania & 0.0121 \\
\hline Lithuania & 0.0097 & 34 & Denmark & 0.0104 \\
\hline Portugal & 0.0074 & 35 & Greece & 0.0101 \\
\hline Syrian Arab Rep. & 0.0071 & 36 & Chile & 0.0081 \\
\hline Austria & 0.0069 & 37 & Austria & 0.0081 \\
\hline Hungary & 0.0067 & 38 & Portugal & 0.0076 \\
\hline New Zealand & 0.0064 & 39 & Syrian Arab Rep. & 0.0074 \\
\hline Sweden & 0.0063 & 40 & Hungary & 0.0068 \\
\hline
\end{tabular}




\begin{tabular}{|c|c|c|c|c|}
\hline \multicolumn{5}{|l|}{ Table 3 continued } \\
\hline Country & $\begin{array}{c}\text { Environmental } \\
\text { degradation index } \\
\text { outcome in } 2000\end{array}$ & $\mathbf{N}$ & Country & $\begin{array}{c}\text { Environmental } \\
\text { degradation index } \\
\text { outcome in } 2005\end{array}$ \\
\hline Finland & 0.0063 & 41 & New Zealand & 0.0067 \\
\hline Israel & 0.0062 & 42 & Azerbaijan & 0.0065 \\
\hline Azerbaijan & 0.0060 & 43 & Finland & 0.0065 \\
\hline Norway & 0.0059 & 44 & Norway & 0.0062 \\
\hline Ireland & 0.0058 & 45 & Ireland & 0.0060 \\
\hline Macedonia & 0.0055 & 46 & Bulgaria & 0.0058 \\
\hline Bulgaria & 0.0055 & 47 & Morocco & 0.0054 \\
\hline Singapore & 0.0050 & 48 & Tanzania & 0.0052 \\
\hline Morocco & 0.0045 & 49 & Macedonia & 0.0051 \\
\hline Bolivia & 0.0036 & 50 & Oman & 0.0047 \\
\hline Ecuador & 0.0035 & 51 & Ecuador & 0.0046 \\
\hline Trinidad \& Tobago & 0.0034 & 52 & Jordan & 0.0029 \\
\hline Eritrea & 0.0031 & 53 & Yemen, Rep. & 0.0027 \\
\hline Oman & 0.0030 & 54 & Moldova & 0.0026 \\
\hline Jordan & 0.0022 & 55 & Estonia & 0.0025 \\
\hline Moldova & 0.0020 & 56 & Mongolia & 0.0016 \\
\hline Yemen, Rep. & 0.0020 & 57 & Luxembourg & 0.0011 \\
\hline Senegal & 0.0013 & 58 & Botswana & 0.0011 \\
\hline Botswana & 0.0009 & 59 & Panama & 0.0009 \\
\hline Luxembourg & 0.0009 & 60 & Kyrgyz Rep. & 0.0009 \\
\hline Kyrgyz Rep. & 0.0009 & 61 & Cyprus & 0.0008 \\
\hline Panama & 0.0009 & 62 & Tajikistan & 0.0007 \\
\hline Tajikistan & 0.0007 & 63 & Albania & 0.0007 \\
\hline Cyprus & 0.0007 & 64 & Eritrea & 0.0005 \\
\hline Albania & 0.0006 & 65 & & \\
\hline
\end{tabular}


Table 4 Change in environmental quality outcome between 2000 and 2005

\begin{tabular}{|c|c|c|c|}
\hline Country & Deterioration & Country & Improvement \\
\hline South Africa & 105.217 & Vietnam & 30.668 \\
\hline Ethiopia & $\begin{array}{l}59.891 \\
\end{array}$ & Estonia & 17.784 \\
\hline Sweden & 53.134 & France & 3.237 \\
\hline Poland & 41.483 & Eritrea & 2.668 \\
\hline Slovak Republic & 38.548 & Germany & 2.605 \\
\hline Malaysia & 33.688 & United Kingdom & 2.296 \\
\hline Indonesia & 12.517 & Denmark & 2.260 \\
\hline Russian Federation & 11.778 & Macedonia & 0.397 \\
\hline Iran, Islamic Rep. & 10.670 & Netherlands & 0.031 \\
\hline Croatia & 9.906 & & \\
\hline United States & 9.330 & & \\
\hline Lithuania & 7.727 & & \\
\hline Czech Rep. & 6.521 & & \\
\hline Slovenia & 6.463 & & \\
\hline Kazakhstan & 5.578 & & \\
\hline Spain & 5.567 & & \\
\hline Belgium & 3.258 & & \\
\hline Turkey & 3.090 & & \\
\hline Latvia & 2.601 & & \\
\hline Korea & 2.448 & & \\
\hline Italy & 1.877 & & \\
\hline Oman & 1.684 & & \\
\hline Japan & 1.500 & & \\
\hline Austria & 1.110 & & \\
\hline Ecuador & 1.048 & & \\
\hline Morocco & 0.889 & & \\
\hline Jordan & 0.778 & & \\
\hline Yemen, Rep. & 0.690 & & \\
\hline Romania & 0.561 & & \\
\hline Azerbaijan & 0.551 & & \\
\hline Moldova & 0.518 & & \\
\hline Ukraine & 0.445 & & \\
\hline Colombia & 0.350 & & \\
\hline Bulgaria & 0.314 & & \\
\hline New Zealand & 0.301 & & \\
\hline Norway & 0.285 & & \\
\hline Syrian Arab Rep. & 0.276 & & \\
\hline Luxembourg & 0.252 & & \\
\hline Finland & 0.210 & & \\
\hline Portugal & 0.202 & & \\
\hline Ireland & 0.183 & & \\
\hline Botswana & 0.131 & & \\
\hline Albania & 0.113 & & \\
\hline Hungary & 0.101 & & \\
\hline Panama & 0.078 & & \\
\hline Cyprus & 0.076 & & \\
\hline Kyrgyz Rep. & 0.057 & & \\
\hline Tajikistan & 0.036 & & \\
\hline
\end{tabular}




\begin{tabular}{|c|c|c|c|c|}
\hline Country & $\begin{array}{l}\text { Environmental } \\
\text { degradation } \\
\text { index outcome } \\
\text { in } 2005\end{array}$ & $\mathbf{N}$ & Country & ESI score \\
\hline China & 0.6970 & $\mathbf{1}$ & Yemen, Rep. & 62.7 \\
\hline United States & 0.5899 & 2 & Ethiopia & 62.2 \\
\hline Ethiopia & 0.3108 & 3 & Saudi Arabia & 62.2 \\
\hline South Africa & 0.2662 & 4 & China & 61.4 \\
\hline Russian Federation & 0.2058 & 5 & Tajikistan & 61.4 \\
\hline Japan & 0.1221 & 6 & Iran, Islamic Rep. & 60.2 \\
\hline Germany & 0.0868 & 7 & Philippines & 57.7 \\
\hline Poland & 0.0775 & 8 & Vietnam & 57.7 \\
\hline Malaysia & 0.0774 & 9 & Korea, Rep. & 57.0 \\
\hline Slovak Rep. & 0.0771 & 10 & Syrian Arab Rep. & 56.2 \\
\hline Philippines & 0.0687 & 11 & Belgium & 55.6 \\
\hline Indonesia & 0.0605 & 12 & Ukraine & 55.3 \\
\hline Sweden & 0.0594 & 13 & Morocco & 55.2 \\
\hline United Kingdom & 0.0581 & 14 & Poland & 55.0 \\
\hline Vietnam & 0.0579 & 15 & Azerbaijan & 54.6 \\
\hline Iran, Islamic Rep. & 0.0530 & 16 & Romania & 53.8 \\
\hline Italy & 0.0497 & 17 & South Africa & 53.8 \\
\hline France & 0.0481 & 18 & Czech Republic & 53.4 \\
\hline Korea, Rep. & 0.0461 & 19 & Turkey & 53.4 \\
\hline Ukraine & 0.0395 & 20 & Macedonia & 52.8 \\
\hline Latvia & 0.0390 & 21 & Jordan & 52.2 \\
\hline Spain & 0.0381 & 22 & Oman & 52.1 \\
\hline Saudi Arabia & 0.0371 & 23 & Kyrgyz Republic & 51.6 \\
\hline Croatia & 0.0311 & 24 & Kazakhstan & 51.4 \\
\hline Turkey & 0.0305 & 25 & Indonesia & 51.2 \\
\hline Kazakhstan & 0.0214 & 26 & Spain & 51.2 \\
\hline Belgium & 0.0208 & 27 & Bulgaria & 51.0 \\
\hline Slovenia & 0.0199 & 28 & Mongolia & 51.0 \\
\hline Czech Rep. & 0.0197 & 29 & Greece & 49.9 \\
\hline Netherlands & 0.0188 & 30 & Italy & 49.9 \\
\hline Lithuania & 0.0174 & 31 & United Kingdom & 49.8 \\
\hline Colombia & 0.0123 & 32 & Tanzania & 49.7 \\
\hline Romania & 0.0121 & 33 & Moldova & 48.8 \\
\hline Denmark & 0.0104 & 34 & Hungary & 48.0 \\
\hline Greece & 0.0101 & 35 & Ecuador & 47.6 \\
\hline Chile & 0.0081 & 36 & Slovak Republic & 47.2 \\
\hline Austria & 0.0081 & 37 & United States & 47.0 \\
\hline Portugal & 0.0076 & 38 & Chile & 46.4 \\
\hline Syrian Arab Rep. & 0.0074 & 39 & Netherlands & 46.3 \\
\hline Hungary & 0.0068 & 40 & Malaysia & 46.0 \\
\hline
\end{tabular}




\begin{tabular}{|c|c|c|c|c|}
\hline \multicolumn{5}{|c|}{ Table 5 continued } \\
\hline Country & $\begin{array}{l}\text { Environmental } \\
\text { degradation } \\
\text { index outcome } \\
\text { in } 2005\end{array}$ & $\mathbf{N}$ & Country & ESI score \\
\hline New Zealand & 0.0067 & 41 & Portugal & 45.8 \\
\hline Azerbaijan & 0.0065 & 42 & France & 44.8 \\
\hline Finland & 0.0065 & 43 & Botswana & 44.1 \\
\hline Norway & 0.0062 & 44 & Russian Fed. & 43.9 \\
\hline Ireland & 0.0060 & 45 & Germany & 43.0 \\
\hline Bulgaria & 0.0058 & 46 & Japan & 42.7 \\
\hline Morocco & 0.0054 & 47 & Slovenia & 42.5 \\
\hline Tanzania & 0.0052 & 48 & Panama & 42.3 \\
\hline Macedonia & 0.0051 & 49 & Denmark & 41.8 \\
\hline Oman & 0.0047 & 50 & Estonia & 41.8 \\
\hline Ecuador & 0.0046 & 51 & Albania & 41.2 \\
\hline Jordan & 0.0029 & 52 & Colombia & 41.1 \\
\hline Yemen, Rep. & 0.0027 & 53 & Lithuania & 41.1 \\
\hline Moldova & 0.0026 & 54 & Ireland & 40.8 \\
\hline Estonia & 0.0025 & 55 & Croatia & 40.5 \\
\hline Mongolia & 0.0016 & 56 & Latvia & 39.6 \\
\hline Botswana & 0.0011 & 57 & New Zealand & 39.0 \\
\hline Panama & 0.0009 & 58 & Austria & 37.3 \\
\hline Kyrgyz Rep. & 0.0009 & 59 & Sweden & 28.3 \\
\hline Tajikistan & 0.0007 & 60 & Norway & 26.6 \\
\hline Albania & 0.0007 & 61 & Finland & 24.9 \\
\hline
\end{tabular}




\begin{tabular}{|l|l|l|l|l|l|}
\hline Table 6 Spearman rank correlation between ESI and environmental degradation risk indices \\
\hline & ESI Score & $\begin{array}{l}\text { GHG } \\
\text { emission } \\
\text { index }\end{array}$ & $\begin{array}{l}\text { Water } \\
\text { pollution } \\
\text { index }\end{array}$ & $\begin{array}{l}\text { Net forest } \\
\text { depletion } \\
\text { index }\end{array}$ & $\begin{array}{l}\text { Environmental } \\
\text { degradation } \\
\text { index }\end{array}$ \\
\hline ESI score & 1 & & & & \\
\hline GHG emission index & $0.2446^{* * *}$ & 1 & & & \\
\hline Water pollution index & 0.1406 & $0.9053^{*}$ & 1 & & \\
\hline Net forest depletion index & 0.0374 & -0.1847 & -0.1226 & 1 & \\
\hline $\begin{array}{l}\text { Environmental degradation } \\
\text { index }\end{array}$ & 0.1378 & $0.8048^{*}$ & $0.7763^{*}$ & $0.3107^{* *}$ & 1 \\
\hline $\begin{array}{l}\text { Note: } 61 \text { countries that have overlapping data for all indices are used to obtain the spearman rank correlations. *, **, } \\
\text { and *** denotes the significance of the spearman rank correlation at 1\%, 5\% and 10\% level respectively. }\end{array}$ \\
\hline
\end{tabular}




\section{Appendix A: Data and normalization procedure}

\begin{tabular}{|l|l|}
\hline \multicolumn{2}{|l|}{ Table A1 Data availability for environmental degradation variables } \\
\hline Variable & Data availability \\
\hline $\mathrm{CO}_{2}$ emissions & $\begin{array}{l}\text { Unbalanced annual data between } 1960 \text { and } 2009 \\
(198 \text { countries for 2009) }\end{array}$ \\
\hline $\begin{array}{l}\text { Methane } \\
\left(\mathrm{CO}_{2} \text { equivalent }\right)\end{array}$ & Balanced data for 135 countries for 1990, 1995, 2000, and 2005 \\
\hline $\begin{array}{l}\text { Nitrous oxide emissions } \\
\left(\mathrm{CO}_{2} \text { equivalent) }\right.\end{array}$ & Balanced data for 135 countries for 1990, 1995, 2000, and 2005 \\
\hline $\begin{array}{l}\text { Other greenhouse emissions }\left(\mathrm{CO}_{2}\right. \\
\text { equivalent) }\end{array}$ & Balanced data for 135 countries for 1990, 1995, 2000, and 2005 \\
\hline $\begin{array}{l}\text { Total GHG emissions } \\
\text { (i.e., sum of } \mathrm{CO}_{2}, \text { methane, nitrous oxide } \\
\text { and other greenhouse emissions) }\end{array}$ & $\begin{array}{l}\text { Overlapping data for all type of greenhouse emissions consist } \\
\text { years } 1990 \text { (110 countries), 1995 (134 countries), 2000 (135 } \\
\text { countries) and 2005 (135 countries) in total of 514 observations. }\end{array}$ \\
\hline $\begin{array}{l}\text { Water pollution } \\
\text { (measured by biochemical oxygen demand } \\
\text { (BOD) })\end{array}$ & $\begin{array}{l}\text { Unbalanced data set for } 101 \text { countries from 1986 to 2007 } \\
\text { (yearly) consisting of } 967 \text { observations }\end{array}$ \\
\hline $\begin{array}{l}\text { Net forest depletion } \\
\text { (measured by the product of unit resource } \\
\text { rents and the excess of roundwood harvest } \\
\text { over natural growth in current US\$) }\end{array}$ & $\begin{array}{l}\text { Balanced annual data set for } 171 \text { countries from } 1970 \text { to } 2010 \\
\text { consisting of } 7011 \text { observations }\end{array}$ \\
\hline
\end{tabular}

\begin{tabular}{|l|l|}
\hline \multicolumn{2}{|l|}{ Table A2 Variables used for overall environmental degradation index and normalization procedure } \\
\hline $\begin{array}{l}\text { Variables used in overall environmental } \\
\text { degradation index }\end{array}$ & Data availability \\
\hline $\begin{array}{l}\text { Total GHG emissions, Water pollution, net } \\
\text { forest depletion }\end{array}$ & $\begin{array}{l}\text { Overlapping data for the overall environmental quality index } \\
\text { consists of unbalanced data for years } 1990 \text { (8 countries) } \\
1995 \text { (41 countries), } 2000 \text { (65 countries) and } 2005 \text { (64 } \\
\text { countries) in total of } 178 \text { observations. }\end{array}$ \\
\hline Normalization procedure & $\begin{array}{l}\text { Highest total greenhouse emission is used to normalize the } \\
\text { total greenhouse emissions } \\
\text { (i.e., China in 2005). }\end{array}$ \\
\hline Total GHG emissions & $\begin{array}{l}\text { The highest total water pollution is used to normalize the } \\
\text { water pollution values } \\
\text { (i.e., China in 2005). }\end{array}$ \\
\hline Water pollution & $\begin{array}{l}\text { The highest net forest depletion value is used to normalize } \\
\text { the net forest depletion values } \\
\text { (i.e., Ethiopia in 2005). }\end{array}$ \\
\hline
\end{tabular}

